Methods: Eleven public rheumatology centers from all of the 5 regions of Brazil enrolled $\sim 100$ consecutive RA patients each (1987 ARA or 2010 ACR-EULAR). This cohort is being followed prospectively for 1 year, with systematic data collection at time $0,6 \pm 1$ months and $12 \pm 1$ months, and registration of all other visits during this 1-year period. Data collection began in 08-2015, using a single online electronic medical record, and included demographic, socioeconomic, clinical, lab, radiographic and therapeutic characteristics, along with functional status, quality of life and adherence to treatment information.

Results: 1125 patients were enrolled (Table), 90\% were female, with a mean age of 56 years and median disease duration of 13 years. Median BMI was 27 $\mathrm{kg} / \mathrm{m}^{2}$, with $64 \%$ of the patients classified as overweight or obese. The interval between symptoms and diagnosis varied from 1 to 457 months (median 12 months). Almost half of the patients were on glucocorticoids, $96 \%$ on DMARDs, with $36 \%$ on biologics. Only $7 \%$ were seronegative for both rheumatoid factor and ACPA. Median HAQ-DI was 0.875 and median DAS28-ESR was 3.5, with $58.6 \%$ of patients presenting moderate or high disease activity.

Table 1. Patients baseline characteristics

\begin{tabular}{lcc}
\hline & $\mathrm{N}$ & \\
\hline Age, years & & \\
Female & 1125 & $56.7(22.1-88.8)$ \\
Current or former smoker & 1125 & $89.5 \%$ \\
BMI, kg/m* & 1125 & $39.6 \%$ \\
Disease duration, years ${ }^{\star}$ & 1055 & $26.6(15.8-56.2)$ \\
Rheumatoid factor+ & 1124 & $12.7(0.7-56.7)$ \\
ACPA+ & 1105 & $78.7 \%$ \\
Erosive disease & 479 & $76.8 \%$ \\
Extra-articular manifestation $\geq 1$ & 1105 & $55.2 \%$ \\
Drugs in use: & 1118 & $23.3 \%$ \\
- Glucocorticoids & & $\%$ \\
- NSAIDs & 1125 & 47.0 \\
- Synthetic DMARDs & 1125 & 9.0 \\
- Methotrexate & 1125 & 90.8 \\
- Biologic DMARDs & 1125 & 66.5 \\
Erythrocyte sedimentation rate (ESR), mm/1st hour $^{*}$ & 1125 & 36.1 \\
C-reactive protein, mg/dL & 933 & $21(1-140)$ \\
DAS28-ESR & 954 & $0.7(0-76.1)$ \\
HAQ-DI $^{*}$ & 932 & $3.5(0.3-8.2)$ \\
\hline
\end{tabular}

${ }^{\star}$ Results in median (range).

Conclusions: The delay in diagnosis may explain the high percentage of patients with moderate or high disease activity and erosive disease. The low level of physical dysfunction observed in this established, predominantly seropositive RA population may be explained by the large proportion of patients on glucocorticoid and biologic therapy. Our findings suggest that, despite current treatment concepts being well known and accepted by Brazilian rheumatologists, there is still a gap in early diagnosis and management of RA.

Disclosure of Interest: None declared

DOI: 10.1136/annrheumdis-2017-eular.1740

\section{AB0321 RELATIONSHIP OF CAROTID FEMORAL PULSE WAVE VELOCITY WITH AGE AND TIME OF EVOLUTION IN PATIENTS WITH RHEUMATOID ARTHRITIS}

C. Ramos ${ }^{1}$, G. Alanis ${ }^{1}$, D. Cardona ${ }^{2}$, S. Totsuka ${ }^{1}$, E. Cardona ${ }^{1}$, F. Pérez $^{1}$, A. Coldivar ${ }^{1}, \mathrm{~J}_{\text {. Gómez }}{ }^{1}, \mathrm{M}$. Vázquez del Mercado ${ }^{1}$. ${ }^{1}$ Physiology, University of Guadalajara; ${ }^{2}$ Physiology, University of Gudalajara, Guadalajara, Mexico

Background: Early vascular aging occurring in Rheumatoid Arthritis (RA) may be a consequence of chronic inflammation. The measurement of Carotid-femoral pulse wave velocity (cfPWV) is the gold standard to evaluate arterial stiffness. Vascular aging is a result of a change in the biomechanical properties of the vascular wall. This process can be accelerated by the accumulated damage of high mechanical stress (high blood pressure), chronic inflammation and comorbidities such as smoking, Diabetes Mellitus and dyslipidemia ${ }^{1}$

Objectives: The aim of this study was to evaluate variations in the CarotidFemoral Pulse Wave Velocity (cfPWV) and it's association to age and time of disease evolution in patients with rheumatoid arthritis.

Methods: RA patients were matched for age and sex with healthy controls. Subjects with a history of smoking, cardiovascular disease, hypertension, diabetes mellitus, cancer, liver disease, thyroid disease and kidney disease were excluded. The cfPWV was calculated using the Pulse Pen ${ }^{\circledR}$ (Diatechne, Italy) device.

Results: We included 76 women with RA and 28 healthy women, mean age (44.3 \pm 10.92 vs. $43.0 \pm 16.26, P=0.654)$. cfPWV demonstrated good correlation with age $(r=0.459, P<0.01)$, disease evolution time $(r=0.311, P=0.008)$, triglycerides $(r=0.289, P=0.03)$, total cholesterol $(r=0.421, P<0.01)$ and atherogenic index $(r=0.320, P=0.02)$. No association with disease activity was found. cfPWV was higher in those patients with $\mathrm{RA}>10$ years evolution compared to patients with $<10$ years of disease evolution and to controls $(P<0.05)$.

Conclusions: A significant association between cfPWV was seen in patients with $\mathrm{RA}$, and was also correlated to age and to a disease evolution $>10$ years long without finding a significant association with increased disease activity.

References:

[1] -Kozakova M, Morizzo C, Guarino D, et al. The impact of age and risk factors on carotid and carotid-femoral pulse wave velocity. Journal of hypertension 2015;33(7):1446-51 doi: 10.1097/HJH.0000000000000582 [published Online First: Epub Date]|.

Disclosure of Interest: None declared

DOI: 10.1136/annrheumdis-2017-eular.6405

\section{AB0322 THE ROLE OF HOMA-IR AND HOMA-ISLET INDICES IN DIFFERENT CARBOHYDRATE METABOLISM DISORDERS DURING GLUCOCORTICOID THERAPY}

\section{G. Nurullina. Kazan Medical State University, KAZAN, Russian Federation}

Background: Diabetogenic effect limits the use of glucocorticoids (GC), especially in patients with diabetes risk factors. At present HOMA index is widely used for the evaluation of insulin resistance (IR) and $\beta$-cell function. HOMA-IR index increase is an indirect measure of IR progression and cardiovascular risk elevation.

Objectives: To evaluate the role of modified HOMA-IR and HOMA-islet indices in different carbohydrate metabolism disorders (CMD) during oral (OGCT) and PULSE (GCPT) glucocorticoid therapy (GCT)

Methods: A prospective study including 118 patients with systemic lupus erythematosus (SLE) $(n=63)$ and systemic vasculitis (SV) $(n=55)$ was performed. Seventy one patients received GCPT (i.v. infusion of $10-15 \mathrm{mg} / \mathrm{kg}$ of prednisolone with $250 \mathrm{ml}$ of normal saline per day, for 3 consecutive days (1 course of 3 sessions); course dose was 1800-3000 mg; 47 patients received oral GC 15-30 $\mathrm{mg} /$ day. HOMA-IR index and $\beta$-cell function (HOMA-islet index) were calculated as follows: Homa-IR $=1.5$ + fasting blood glucose $(\mathrm{mmol} / \mathrm{l}) \times$ fasting C-peptide level $(\mathrm{pmol} / \mathrm{l}) / 2800$. HOMA-islet $=0.27 \times$ fasting $\mathrm{C}$-peptide level $(\mathrm{pmol} / \mathrm{l}) /($ fasting blood glucose $(\mathrm{mmol} / \mathrm{l})-3,5)$.

Results: GCPT was associated with less CMD compared to OGCT. Impaired fasting glucose (IFG) was observed in $7(9.9 \%)$ and $9(19.1 \%)$, impaired glucose tolerance (IGT) - in $9(12.7 \%)$ and $14(29.8 \%)$ and diabetes mellitus (DM) - in 9 $(12.7 \%)$ and $13(27.7 \%)$ patients in GCPT and OGCT groups, respectively. There was a significant decrease of HOMA-islet during glycemic peak in DM patients from 13.96 to 6.17 after GCPT $(p<0.05)$, compared to insignificant changes in other groups. Decrease of HOMA-islet index reflects a disturbance of overall functional activity of $\beta$-cells in DM patients. After a course of GCPT HOMA-islet index was significantly lower in DM patients compared to patients with no CMD (11.8 vs. 15.4), as GCPT is associated with a decrease of $\beta$-cell function which does not return to baseline as a consequence of $\beta$-cell reserve depletion. No rapid decrease of $\beta$-cell function was observed in OGCT group, instead there was a compensatory increase, which was insufficient to maintain normoglycia because of high insulin resistance. C-peptide, HOMA-IR and HOMA-islet levels in OGCT patients demonstrated the same trend as in GCPT patients. Significant differences were observed in patients with IGT and DM before and after oral glucose tolerance test (OGTT) on C-peptide (1042 pmol/l vs. $1978 \mathrm{pmol} / \mathrm{l}$ in IGT; $1306 \mathrm{pmol} / \mathrm{l}$ vs. $2286 \mathrm{pmol} / \mathrm{l}$ in DM) and HOMA-IR (4.53 vs. 9.81 in IGT; 5.6 vs. 11.27 in DM patients), whereas in patients without $\mathrm{CMD}$ and in patients with IFG, C-peptide before OGTT was $489 \mathrm{pmol} / \mathrm{l}$ vs. $743 \mathrm{pmol} / \mathrm{l}$, after - $1295 \mathrm{pmol} / \mathrm{l}$ vs. $1488 \mathrm{pmol} / \mathrm{l}, \mathrm{HOMA}-\mathrm{IR}-2.59$ vs. 2.88 before OGTT and 2.88 vs. 5.85 after the test in the absence of CMD and in IFG patients, respectively. A significant decrease of $\beta$-cell function was observed in DM patients, reflected by a decrease of HOMA-islet index after OGTT compared to baseline (147 vs. 78.4).

Conclusions: Evaluation of blood glucose level, which was normal in all included patients, and isolated C-peptide evaluation are insufficient for the evaluation of carbohydrate metabolism before GCPT and long-term OGCT. The evaluation of modified HOMAA-IR and HOMA-islet indices before the start of intensive GC treatment and during OGCT may improve early detection of risk groups for serious CMDs - IGT and DM.

Disclosure of Interest: None declared

DOI: 10.1136/annrheumdis-2017-eular.572

\section{AB0323 CARBOHYDRATE METABOLISM AND GLUCOCORTICOID THERAPY IN PATIENTS WITH SYSTEMIC INFLAMMATORY DISEASES}

\section{G. Nurullina. Kazan Medical State University, Kazan, Russian Federation}

Background: Glucocorticoid therapy (GCT) is one of the risk factors of carbohydrate metabolism disorders (CMD) in patents with systemic inflammatory diseases. CMD development is a concern not only with long-term therapy, but also during intensive short-term GC administration, which can lead to different CMDs, including impaired glucose tolerance (IGT) and diabetes mellitus (DM).

Objectives: to evaluate the prevalence of CMD after long-term and intensive GC treatment (GCT) in patients with systemic lupus erythematosus (SLE), systemic vasculitis (SV) and chronic glomerulonephritis (CGN).

Methods: Ninety eight patients with systemic inflammatory diseases were included (SLE - 53, SV - 35), among them 68 received GC pulse-therapy (GCPT) (1 series of 3 sessions), and 30 - oral GCT (OGCT). All patients underwent standard clinical and laboratory evaluation, oral glucose tolerance test (OGTT), evaluation of C-peptide, HOMA-IR and HOMA-islet indices.

Results: CMDs developed less often in patients receiving GCPT compared to long-term OGCT $(p=0.035)$. In patients receiving OGCT the most prevalent CMDs were IGT and DM - in $9(30.0 \%)$ and $8(26.7 \%)$ patients respectively, which 
was significantly higher compared to patients in GCPT group - 7 (10.3\%) and 6 $(8.8 \%)$ respectively $(p=0.038$ and $p=0.049)$. Baseline $C$-peptide was elevated in patients who developed IGT after a course of GCPT ( $850 \mathrm{pmol} / /$ before GCPT, $4099 \mathrm{pmol} / \mathrm{l}$ 4-6 hours after GCPT and $1904 \mathrm{pmol} / \mathrm{l}$ after a 3-days course of GCPT) or DM (1050 pmol//, $3170 \mathrm{pmol} / \mathrm{l}$ and $1796 \mathrm{pmol} / \mathrm{l}$ before GCPT, at peak blood glucose level and after a 3 -days course of GCPT, respectively) $(p<0.05)$. $\mathrm{C}$-peptide remained normal in the absence of CMD and in IGT patients.

Baseline HOMA-IR index was elevated in patients with IGT (4.52, 17.47, 9.67 before GCPT, at peak blood glucose level and after a 3-days course of GCPT, respectively) and DM $(5.04,15.2,10.4$ respectively) $(p<0.05)$, and normal in patients without $\operatorname{CMD}(2.2,5.84$ and 4.01 respectively) and patients with impaired fasting glucose (IFG) $(2.46,7.08$ and 5.46$)$.

HOMA-islet index analysis revealed that in the absence of CMD and at earlier stages of CMDs (IFG, IGT) insulin resistance is compensated via an increase of $\beta$-cell secretory activity. In DM patients there is a trend towards decreased $\beta$-cell secretory activity, which is associated with a significant decrease of HOMA-islet index to 64,6 at peak blood glucose levels after GCPT compared to baseline level (170) $(p<0.05)$. C-peptide, HOMA-IR and HOMA-islet index levels in OGCT patients demonstrated same trend as in GCPT patients. Significant differences were observed in patients with IGT and DM before and after oral glucose tolerance test (OGTT) on C-peptide (1042 pmol// vs. $1978 \mathrm{pmol} / \mathrm{l}$ in IGT; $1306 \mathrm{pmol} / \mathrm{l}$ vs. $2286 \mathrm{pmol} / \mathrm{l}$ in DM) and HOMA-IR (4.53 vs. 9.81 in IGT; 5.6 vs. 11.27 in DM patients), whereas in patients without CMD and in patients with IFG, C-peptide before OGTT was $489 \mathrm{pmol} / \mathrm{l}$ vs. $743 \mathrm{pmol} / \mathrm{l}$, after $-1295 \mathrm{pmol} / \mathrm{l} \mathrm{vs}$. $1488 \mathrm{pmol} / \mathrm{l}$, HOMA-IR -2.59 vs. 2.88 before OGTT and 2.88 vs. 5.85 after the test in the absence of CMD and in IFG patients, respectively. A significant decrease of $\beta$-cell function was observed in DM patients, reflected by a decrease of HOMA-islet after OGTT compared to baseline (147 vs. 78.4 ).

Conclusions: GCT leads to IGT and DM in patients with increased IR both during GCPT and long-term OGCT. Long-term OGCT is associated with more CMDs compared to GCPT.

Disclosure of Interest: None declared

DOI: 10.1136/annrheumdis-2017-eular.5748

\section{AB0324 IS LOW SERUM VITAMIN D LEVEL ASSOCIATED WITH INCREASED NEUROPATHIC PAIN IN RHEUMATOID ARTHRITIS PATIENTS? A CROSS-SECTIONAL STUDY}

H. Yesil ${ }^{1}$, U. Sungur ${ }^{2}$, S. Akdeniz ${ }^{3}$, G. Gurer ${ }^{3}$, B. Yalcın ${ }^{4}$, U. Dundar ${ }^{1} .{ }^{1}$ Physical Medicine and Rehabilitation, Afyon Kocatepe University, Afyonkarahisar;

${ }^{2}$ Physical Medicine and Rehabilitation, Ege University, Faculty of Medicine, Izmir; ${ }^{3}$ Physical Medicine and Rehabilitation, Adnan Menderes University, Faculty of Medicine, Aydın; ${ }^{4}$ Afyon Kocatepe University, Afyonkarahisar, Turkey

Background: Rheumatoid arthritis (RA) is a systemic, autoimmune, progressive condition characterised by progressive synovitis with resultant joint destruction, functional disability and significant pain. Recent experimental data indicates that there may be a neuropathic component of pain perception in RA.

Objectives: The aim of this study was to examine the development of neuropathic pain (NP) in patients with RA and its relationship with vitamin $\mathrm{D}$.

Methods: We used the Leeds assessment of neuropathic symptoms and signs (LANSS) questionnaire to evaluate NP in 93 patients with RA. Clinical parameters included general demographics, and disease activity scores were evaluated. The patients also completed Short form-36 survey, and Health Assessment Questionnaire.

Results: Of all the patients who were eligible for the study, 75 were female $(80.6 \%)$. Mean serum vitamin $\mathrm{D}$ level of the participants was calculated to be $22.8 \pm 11.9 \mathrm{ng} / \mathrm{mL}$. According to the LANSS questionnaire 31 patients $(33.3 \%)$ were classified as having NP. There was a negative correlation between vitamin $D$ levels and LANSS value $(p=0.001)$. We have determined that patients with vitamin $D$ serum levels below $20 \mathrm{ng} / \mathrm{mL}$ have significantly higher NP positivity rate $(p=0.012)$, besides they have 5.8 times more risk of developing NP when compared to patients with vitamin $D$ serum levels $\geq 30 \mathrm{ng} / \mathrm{mL}$.

Conclusions: We conclude that Vitamin D deficiency is prevalent in RA patients with NP. Once it is the right diagnosis, Vitamin D deficiency treatment is relatively easy, safe, inexpensive and with satisfactory outcomes; therefore, an underlying vitamin D deficiency should be explored in the etiology of NP in patients with RA. References:

[1] Bellucci E, Terenzi R, La Paglia GM, Gentileschi S, Tripoli A, Tani C, Alunno A. One year in review 2016: pathogenesis of rheumatoid arthritis. Clin Exp Rheumatol. 2016; 34(5):793-801.

[2] Koop SM, Klooster PM, Vonkeman HE, Steunebrink LM, van de Laar MA. Neuropathic-like pain features and cross-sectional associations in rheumatoid arthritis. Arthritis Research \& Therapy.2015; 17:237.

[3] Shehab D, Jarallah KA, Abdella N, Mojiminiyi OA, Mohamedy HA. Prospective Evaluation of the Effect of Short-Term Oral Vitamin D Supplementation on Peripheral Neuropathy in Type 2 Diabetes Mellitus. Med Princ Pract. 2015; 24:250-256.

Disclosure of Interest: None declared

DOI: 10.1136/annrheumdis-2017-eular.4395

\section{AB0325 TREAT TO TARGET AND THE REAL LIFE EXPERIENCE - DATA FROM A COHORT OF RHEUMATOID ARTHRTIS PATIENTS IN SOUTH EAST ROMANIA (CONSTANTA COUNTY)}

V.C. Suta ${ }^{1,2}$, I.-T. Andronache ${ }^{1}$, M. Suta ${ }^{2} \cdot{ }^{1}$ Rheumatology Department, IInd Internal Medicine Clinic, "St. Apostol Andrei" Emergency Clinical County Hospital Constanta; ${ }^{2}$ Faculty of Medicine, "OVIDIUS" University Constanta, Constanta, Romania

Background: Treatment target in rheumatoid arthritis (RA) is remission or low disease activity. Considering that there is no quantitative "gold standard " for measuring the disease activity, monitoring and evaluation of RA patients is made through composite scores, which have an important subjective component. Moreover, the laboratory investigations used (ESR and CRP) are commonly discordant with the clinical findings

Objectives: To evaluate disease activity and establish relations between disease activity scores and their components in RA patients

Methods: We performed a transversal study which included 447 RA patients (aged 18 to 86-years-old) admitted to our Rheumatology Department between January 2014 and December 2015. Patients' evaluation was performed by the rheumatologist. All the data obtained from the medical history, clinical examination, laboratory tests and imaging studies was recorded at the same date. All patients signed a dated informed consent at the time of admission.

Results: The study included 447 patients, mean age $62.13 \pm 11.44,85 \%$ women, accounting for a female:male ratio ( $\mathrm{F}: \mathrm{M})$ of almost 6:1 (5.7:1) with an average disease duration of $10,75 \pm 8,85$ years. $48 \%$ of our patients presented with normal CRP values $(\leq 0.5 \mathrm{mg} / \mathrm{dl})$ and values of $\leq 1 \mathrm{mg} / \mathrm{dl}$ for CRP, compatible with Boolean remission, were present in $66.6 \%$ of the patients. A significant percentage of our sample population (194 patients: $43.4 \%$ ) registered normal ESR values ( $\leq 28$ $\mathrm{mm} / \mathrm{h}$ )

Remission and LDA were registered in $18.1 \%$ up to $29.8 \%$.of the patients, depanding on the score used. The lowest rate of remission and low activity is registered through the DAS28 ESR evaluation (18.1\%). The other three scores outline similar percentages for T2T group of patients: $27.1 \%$ (SDAI), $28.7 \%$ (CDAI), and $29.7 \%$ (DAS28 CRP). The LDA group is characterized in our study by a small number of swollen joints $(<1)$, medium-normal ESR values $(<30 \mathrm{~mm} / \mathrm{h})$ and CRP values $<1 \mathrm{mg} / \mathrm{dl}$ (with the exception of SDAl). Consequently, patients with low activity based on the afore mentioned scores meet remission according to Boolean definition.

Conclusions: The disease activity and implicitly the remission rate are appreciated differently depending on the scale used. The limit between remission and low disease activity is fragile, influenced mainly by the purely subjective components of the assessment instruments. The important differences between the subjective and objective components of the evaluation scales recommend the supplementation of methods used in order to emphasize the real degree of joint inflammation.

\section{References:}

[1] Jonathan Kay, Olga Morgacheva, Daniel E Furst et al. Clinical disease activity and acute phase reactant levels are discordant among patients with active rheumatoid arthritis: acute phase reactant levels contribute separately to predicting outcome at one year. Arthritis Research \& Therapy 2014, 16:R40.

[2] Tuulikki Sokka et al. Remission and Rheumatoid Arthritis. Data on Patients Receiving Usual Care in Twenty-Four Countries. ARTHRITIS \& RHEUMATISM Vol. 58, No. 9, September 2008, pp 2642-2651.

[3] Glenn Haugeberg et al. Ten years of change in clinical disease status and treatment in rheumatoid arthritis: results based on standardized monitoring of patients in an ordinary outpatient clinic in southern Norway. Arthritis Research \& Therapy (2015) 17:219.

Disclosure of Interest: None declared

DOI: 10.1136/annrheumdis-2017-eular.6920

\section{AB0326 INFLUENCE OF NONSTEROIDAL ANTI-INFLAMMATORY DRUGS ON ARTERIAL STIFFNESS IN PATIENTS WITH RHEUMATIC DISEASES}

J.N. Kim, J.-Y. Choe, S.-K. Kim, S.-H. Park, H. Lee, C.U. Lee, J.-W. Kim. Division of Rheumatology, Department of Internal Medicine, Catholic University of Daegu School of Medicine, Daegu, Korea, Republic Of

Background: The association with adverse cardiovascular (CV) events and NSAIDs has been the topic of much debate.

Objectives: The aim of the present study was to investigate the effects of continuing NSAIDs therapy on predictable parameters for CV events.

Methods: We enrolled 155 patients with variable rheumatic diseases (95 rheumatoid arthritis, 49 systemic lupus erythematosus, 3 behçet's disease, 3 gout, 5others.) who were free from established $\mathrm{CV}$ diseases and had taken cardiovascular function tests from June 2015 to June 2016. They were divided into two groups depending on whether or not to have taken NSAIDs therapy for at least 5 years: NSAIDs taking group (91 patients) vs. non NSAIDs taking group (64 patients). For evaluating heart function, transthoracic echocardiography was used. Arterial stiffness was assessed using brachial-ankle pulse wave analysis. Results: There were no significant differences in blood pressure, serum creatinine, serum hemoglobin, total cholesterol, erythrocyte sediment rate, C-reactive protein, disease duration, age, and smoking history between the groups. The NSAIDs 